\title{
Original
}

\section{Effects of Different Dental Alloys on Cytotoxic and Apoptosis Related Genes Expression in L929 Cells}

\author{
Xingya Jia ${ }^{1)}$, Qiang Wang ${ }^{1,2)}$, He Meng ${ }^{1)}$, Hao Sun ${ }^{1)}$ and Desong Zhan ${ }^{1)}$ \\ ${ }^{1}$ School of Stomatology, China Medical University, Nan Jing North Street 117\#, He Ping District, Shenyang 110002, China. \\ 2) Institute of Metal Research, Chinese Academy of Sciences, Shenyang 110016, China. \\ (Accepted for publication, july 29, 2010)
}

\begin{abstract}
Cytotoxicity is one of the most important problems in medical metal materials. Effect of different dental alloys on cytotoxic of L929 cells was evaluated by in vitro cytotoxicity-test (MTT method). Metal ion concentration was one of the factors leading to occurrence of cell toxicity. Thus metal ion concentration in cell culture fluid at different intervals of immersion periods were detected by inductively coupled plasma mass spectrometry (ICP-MS). For different medical metals, RT-PCR method was also used to analysis mRNA expression of L929 cells'caspase-3, caspase- 8 and caspase-9. The results indicated that MTT test found little optical density (OD) value difference for different alloys at different time points. The cytotoxicity of $\mathrm{Cu}$ alloy group was Grade 4 and those of other groups were all Grade 0 after 48 hours culture. The mRNA levels of caspase- 8 had no change in all groups. The mRNA levels of caspase- 3 and caspase- 9 were as follows from low to high: $\mathrm{Cu}$ alloy, the negative control and Au alloy, Co-Cr alloy, Ag-Pd alloy, and Ni-Cr alloy after 48 hours' culture. It is concluded that metal ions of the studied dental alloys may induce cell apoptosis by different degree through mitochondrion pathway. Apoptosis related genes expression of L929 cells was affected by ion concentration in cell culture fluid.
\end{abstract}

Key words: Dental alloys, ICP, Fibroblast cell L929, Apoptosis

\section{Introduction}

Corrosion inevitably occurs when dental alloys functions in mouth, which would increase the metal ion concentration in oral environment. Ion accumulation may lead to occurrence of cell toxicity. In vitro cytotoxicity-test (MTT method) was one of the important and effective methods to evaluate the biocompatibility of medical materials ${ }^{1,2)}$. L929 cells were widely used in MTT method. ISO 10993 (Part 5) also recommended to use the established cell lines in cell toxicity experiment. The biocompatibility of impression materials was evaluated by Coppi $\mathrm{C}^{3)}$. HuangTH et al studied root canal filling materials and pointed out that $\mathrm{Ca}(\mathrm{OH})_{2}$ coupled with Iodoform was a better selection ${ }^{4)}$. However, MTT method was influenced by many factors such as cell types, number of cells, culture time and detection wavelength ${ }^{5}$, 6). Clifford and Dowwes ${ }^{7)}$ found that the repeatation were not good when applied in orthopedic surgery materials. With the rapid development of molecular biology, the mothods of the biocompatability study of biomaterials have been more and more diversification and their evaluation have been raised from the cell

Correspondence to: Prof. Desong Zhan, School of Stomatology, China Medical University, Nan Jing North Street 117\#, He Ping District, Shenyang 110002, China. Te1: 86 2422891583, E-mail: zhandesong@126.com level to molecular level. It was found that cell behaviors were affected by surface properties of medical materials by molecular biology ${ }^{8)}$. RT-PCR was proposed and widely used to evaluate cell toxicity. On the other hand, cell toxicity was impacted by metal ion concentration or accumulation in oral environment. The purpose of the paper is to study the effects of different dental alloys on cytotoxic and apoptosis related genes expression of L929 cells. ICP-MS was used to analyze the impacting factors related to cell toxicity.

\section{Materials and Methods}

Cell lines L929 were cultured in RPMI1640 medium containing $100 \mathrm{IU} / \mathrm{mL}$ penicillin, $100 \mathrm{mg} / \mathrm{mL}$ streptomycin sulphate and $10 \%$ (vol/vol) fetal bovine serum (FBS). Then, the cells were maintained at $37^{\circ} \mathrm{C}$ with $5 \% \mathrm{CO}_{2}$ in air in a humidi' ûed incubator. The cytotoxicity tests were carried out by indirect contact. The dental alloys including composition used in our experiments were summarized in Table.1. Extracts of the five dental materials were prepared using RPMI1640 medium containing serum as the extraction medium with the surface area of extraction medium ratio $3 \mathrm{~cm}^{2} / \mathrm{ml}$ in a humidified atmosphere with $5 \% \mathrm{CO}_{2}$ at $37{ }^{\circ} \mathrm{C}$ for 168 hours. The supernatant fluid was withdrawn and 
J.Hard Tissue Biology Vol. 19(2):95-100, 2010

Table 1. Composition and manufacturer of the dental alloys used in our experiments

\begin{tabular}{llll}
\hline & Dental Alloys & \multicolumn{1}{c}{ Composition (wt. \%) } & Company \\
\hline A & Au alloy & Au86.2-Pt11.5-Zn1.5-Ru0.4-Ta0.3-Mn0.1 & Heraeus \\
B & Ag-Pd alloy & $\mathrm{Ag} 21.5-\mathrm{Pd} 52.2-\mathrm{Au} 15.0-\mathrm{Sn} 4.0-\mathrm{In} 6.0-\mathrm{Ga} 1.0-\mathrm{Ru} 0.3$ & Heraeus \\
$\mathrm{C}$ & $\mathrm{Co}-\mathrm{Cr}$ alloy & $\mathrm{Co} 64.6-\mathrm{Cr} 29.0-\mathrm{Mo} 4.5$ & Stellite \\
$\mathrm{D}$ & $\mathrm{Ni}-\mathrm{Cr}$ alloy & $\mathrm{Ni}(60 \sim 64)-\mathrm{Cr}(19 \sim 23)-\mathrm{Mo}(9 \sim 11)$ & Stellite \\
$\mathrm{E}$ & $\mathrm{Cu}$ alloy & $\mathrm{Cu}(80 \cdot 87)-\mathrm{Zn}\left(12 \cdot \bullet^{`} 20\right)$ & Stellite \\
\hline
\end{tabular}

Table 2. Sequence of PCR primers

\begin{tabular}{llc}
\hline & \multicolumn{1}{c}{ Sequence of primers (5'-3') } & bp \\
\hline caspase-3 & F-5'-TGTCATCTCGCTCTGGTACG-3' & \\
& R-5'-AAATGACCCCTTCATCACCA-3' & 199 \\
caspase-8 & F-5'-GTGAAGAACTGCGTTTCCTACC-3' & \\
& R-5'-AGCTTCTTCCGTAGTGTGAAGG-3' & 206 \\
caspase-9 & F-5TGCACTTCCTCTCAAGGCAGGACC-3' & \\
& R-5'-TCCAAGGTCTCCATGTACCAGGAGC-3' & 206 \\
GAPDH & F-5'ACCACAGTCCATGCCATCAC-3' & \\
& R-5'TCCACCACCCTGTTGCTGTA-3' & 439 \\
\hline
\end{tabular}

centrifuged to prepare the extraction medium, then refrigerated at $4^{\circ} \mathrm{C}$ before the cytotoxicity test. The control groups involved the use of RPMI1640 medium as negative controls and $0.64 \%$ phenol RPMI1640 medium as positive controls. Cells were incubated in 96 -well cell culture plates at $5 \times 10^{3}$ cells $/ 100 \mathrm{ml}$ medium in each well and incubated for $48 \mathrm{~h}$. After that, $10 \mathrm{ml}$ MTT was added to each well. The samples were incubated with MTT for $4 \mathrm{~h}$ at $37^{\circ} \mathrm{C}$, then $150 \mathrm{ml}$ DMSO was added in each well for $20 \mathrm{~min}$. The spectrophotometrical absorbance of the samples was measured by microplate reader (Bio-RAD680) at $490 \mathrm{~nm}$. The OD values were analyzed by SPSS V13.0 software.

The mRNA expression of cells' caspase-3, caspase- 8 and caspase-9 were detected. Total RNA was prepared using a PCR kit (TAKARA ver 3.0, China). Amplification by PCR was started with an initial incubation at $94^{\circ} \mathrm{C}$ for $30 \mathrm{~s}$, and then $55^{\circ} \mathrm{C}$ for $30 \mathrm{~s}$ and $72^{\circ} \mathrm{C} 1 \mathrm{~min}$ for 30 cycles. Primers were designed using the sequence information as shown in Table.2. Metal ion concentration in cell culture fluid at different intervals of immersion periods were detected by plasma atomic emission spectrometry (ICP-AES; SPS-1500VR, Seiko Instruments Inc., Japan) in order to analyze the effects of ion concentration on cytotoxic and apoptosis related genes expression of L929 cells.

\section{Results}

Fig.1 shows cell growth curves of L929. The results of three independent experiments groups exhibit good consistency. It can be seen that the difference was not obviously when less than 4000 cells were cultivated in each well. However, the OD value was
Table 3. OD value in MTT measurement

\begin{tabular}{cccc}
\hline & OD value & P \% & grade \\
\hline A & $1.530 \pm 0.084$ & 98.90 & 0 \\
B & $1.478 \pm 0.075$ & 95.54 & 0 \\
C & $1.512 \pm 0.080$ & 97.73 & 0 \\
D & $1.425 \pm 0.096$ & 99.87 & 0 \\
E & $0.089 \pm 0.007$ & 5.75 & 4 \\
F & $1.547 \pm 0.117$ & 100 & 0 \\
\hline
\end{tabular}

decreased when more than 7000 cells were cultivated in each well. Thus the cell concentration used in our experiments was $6 \times 10^{4}$ / $\mathrm{ml}$.

The cell growth behavior was observed by optical microscope. It was found that the cells grew well except these in group E. Table 3 shows the OD value in MTT measurement. The OD value of group $E$ is lower than that of other groups $(p<0.05)$. The difference between other groups is little $(p>0.05)$. The cell cytotoxicity of group $\mathrm{E}$ is grade 4 while these of other groups are grade 0 . The results indicated that the cytotoxicity of $\mathrm{Cu}$ alloy group was in Grade 4 and those of the other groups were all in Grade 0 after 48 hours culture.

Figure. 2 shows the electrophoresis graphs of L929 cells' caspase-3, caspase- 8 and caspase- 9 . The relative gray value was listed in Table 4 determined by gel imaging system (Alpainnotech chemi Imager, USA). The mRNA levels of caspase-3 and caspase9 were as follows: $\mathrm{E}<\mathrm{F}<\mathrm{A}<\mathrm{C}<\mathrm{B}<\mathrm{D}$. The difference between 
Xingya Jia et al.: Effects on Cytotoxic and Apoptosis Related Genes Expression

Table 4. Relative gray value of caspase- 3 , caspase- 8 and caspase- 9 of different dental materials

\begin{tabular}{ccccc}
\hline & & \multicolumn{2}{c}{ Relative gray value } & \\
\cline { 3 - 3 } & & caspase-3/GAPDH & caspase-8/GAPDH & caspase-9/GAPDH \\
\hline A & $0.528 \pm 0.013$ & $0.850 \pm 0.029$ & $0.574 \pm 0.013$ \\
B & $0.673 \pm 0.009$ & $0.846 \pm 0.014$ & $0.703 \pm 0.018$ \\
C & $0.615 \pm 0.007$ & $0.867 \pm 0.036$ & $0.617 \pm 0.009$ \\
D & $0.803 \pm 0.037$ & $0.860 \pm 0.014$ & $0.811 \pm 0.037$ \\
E & $0.474 \pm 0.001$ & $0.826 \pm 0.016$ & $0.532 \pm 0.041$ \\
F & $0.527 \pm 0.003$ & $0.862 \pm 0.009$ & $0.578 \pm 0.010$ \\
\hline
\end{tabular}

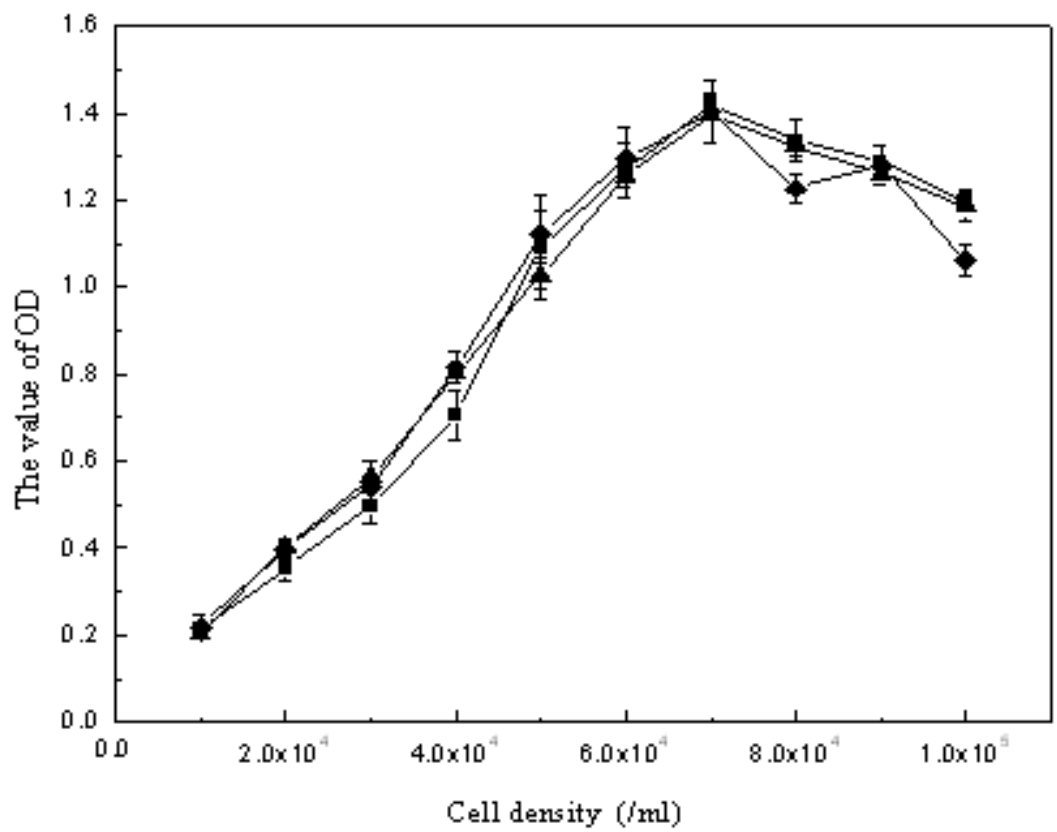

Figure 1. Cell growth curves of L929
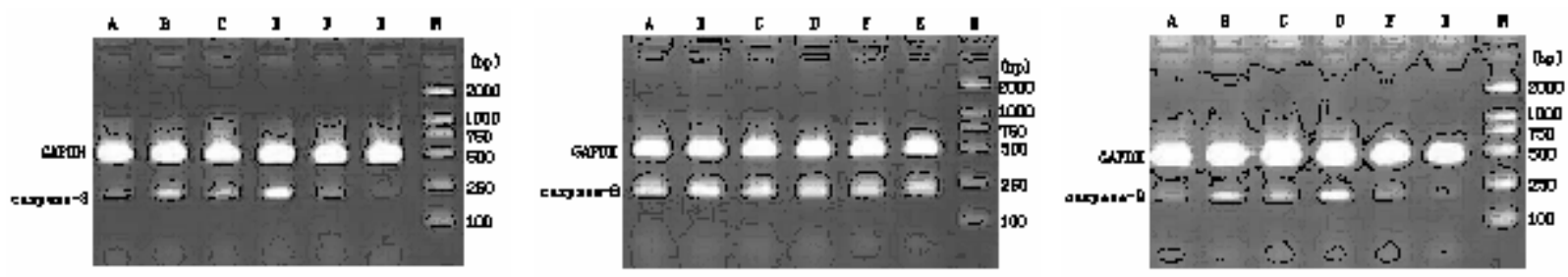

Figure 2. Electrophoresis graphs of L929 cells' caspase-3, caspase-8 and caspase-9.

$\mathrm{F}$ and A group is little while the difference between other groups is obviously $(\mathrm{P}<0.05)$. However, the expression of caspase- 8 of all groups exhibits no significant difference.

\section{Discussion}

Biocompatibility relating to the reaction properties of the nonactive materials with life body is always the key theme in biomaterials study. The biomedical materials must be safe and the reaction must be host acceptable. Thus biological evaluation is essential for biomaterials. The effect of the metal alloys on life body was dependent on the accumulated released ions caused by corrosion. MTT method was commonly used to evaluate cell toxicity first proposed by Mosroam in 1983. In MTT experiment, cell growth curve should be determined first in order to select the 

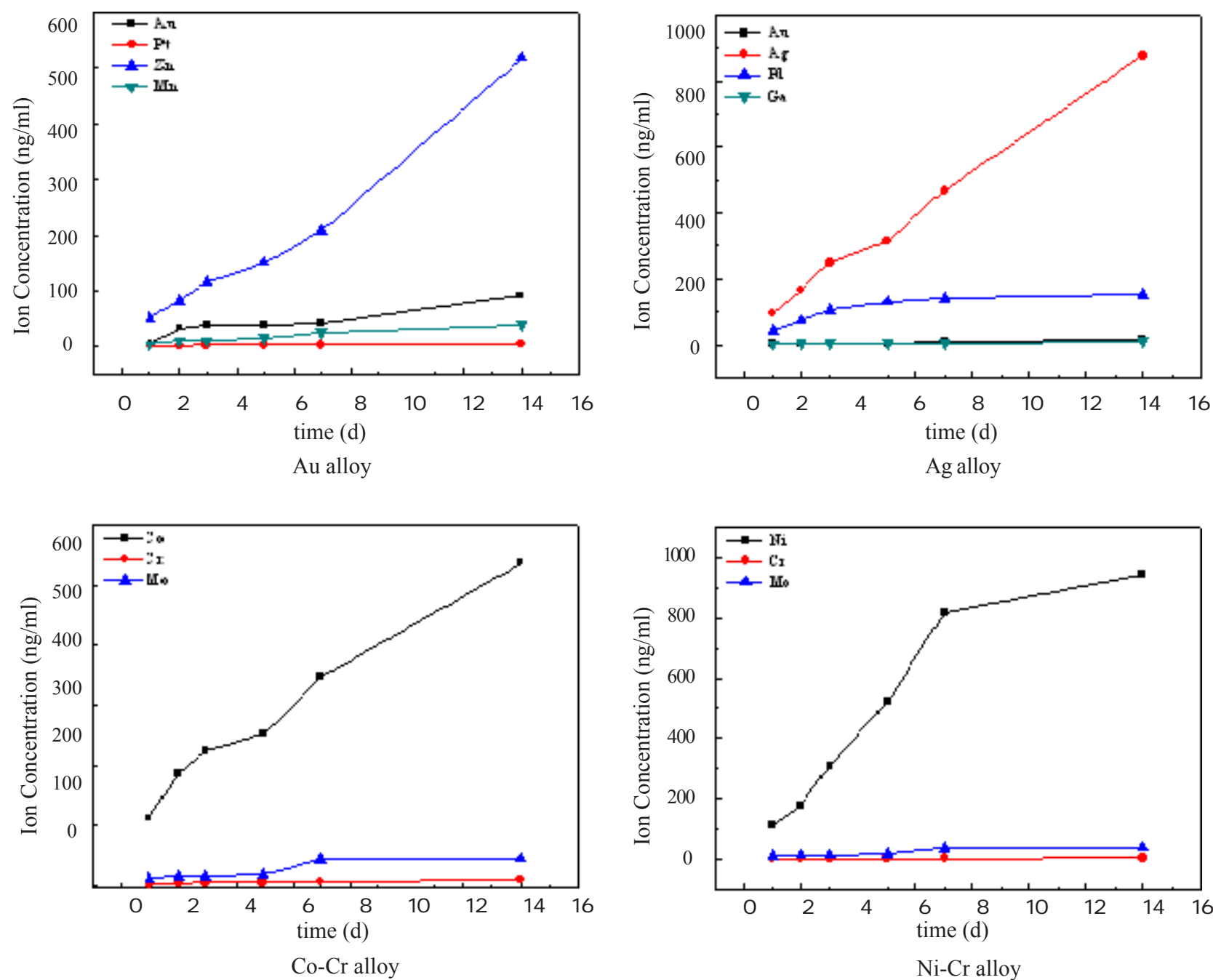

Figure 3. Ion concentration of alloys during the immersion in cell medium for 7 days

optimized cell concentration. Cell fusion would occur if cell concentration is high leading to unchanged or decreased cellular total metabolic rates. In our test, the cell concentration was $6 \times 10^{4} /$ $\mathrm{ml}$. Large number of samples can be detected and analyzed. The establishment of a systematic evaluation of medical materials effect on molecular, cell and human body is the trend and ultimate goal. Thus biocompatibility study by molecular biology was proposed. It was proved that cells behaviors were adjusted by materials surface conditions ${ }^{8)}$. Chou et $\mathrm{al}^{9)}$ indicated that the special nature of materials affected the cells regulation. Li Ning ${ }^{10)}$ observed that molecular biology experiments such as total RNA extraction were more sensitive than traditional cell experiments in cytotoxicity measurement. Shinya Kato et $\mathrm{a}^{11)}$ reported that the expression of HSPmRNA is one of the important indicators of reactions between materials and cells. He studied the mRNA expressions of HeLaS3 cells' HSP70A, HSP 70B, HSP90 and HSP 47. The results showed that the HSP mRNA expression of HeLaS3 cells cultivated on hydrophilic materials was higher than that on the hydrophobic materials.

In the paper, it was concluded that the detection of materials effect on cells on molecular level by RT-PCR was more sensitive compared with that on cell level by MTT method. The effect of five dental alloys on the mRNA expression of caspase$3 \cdot$ Acaspase- 8 and caspase- 9 was studied. The expression of caspase-3 and caspase- 9 was increased which means poor biocompatibility of materials. The cytotoxicity of $\mathrm{Cu}$ alloy group was Grade 4 while the expression of caspase- 3 and caspase- 9 was decreased. The reason was that most of the cells in extraction media of $\mathrm{Cu}$ alloy were necrosis and late apoptotic cells. The same result was reported by Domina and Emanuele et $\mathrm{al}^{12,13)}$. The expression of caspase- 3 and caspase- 9 was increased while that of caspase- 8 kept unchanged, which indicated that the alloy could lead to apoptosis and might be related to mitochondrial apoptotic pathways. The results displayed that precious metal alloys, inert metals or metals which can easily be oxided to form protective film exhibited better corrosion resistance. Thus the expression of 
Xingya Jia et al.: Effects on Cytotoxic and Apoptosis Related Genes Expression

caspase- 3 and caspase- 9 of gold alloy was lower than that of $\mathrm{Ni}$ $\mathrm{Cr}$ alloy. Apoptosis caused by gold alloy was far lower compared with $\mathrm{Ni}-\mathrm{Cr}$ alloy groups. Isabelle Catelas et al ${ }^{14)}$ demonstrated that $\mathrm{Co}^{2+}$ and $\mathrm{Cr}^{3+}$ induce macrophage apoptosis in vitro at $24 \mathrm{~h}$, with the implication of a caspase-3 pathway. Isabelle Catelas et $\mathrm{al}^{15)}$ also found that $\mathrm{Co}^{2+}$ is more toxic than $\mathrm{Cr}^{3+}$, inducing necrosis at much lower concentrations than $\mathrm{Cr}^{3+}$ because of their differences in af' ûnity with serum proteins that could influence their mechanisms of cell penetration andtoxicity. Mekala Gunaratnam et $\mathrm{al}^{16)}$ showed that $\mathrm{Cr}$ VI induces apoptosis at low concentrations and necrosis at higher concentrations by damage to the cell cytoskeleton. Ni almost exclusively induced necrosis at $500 \mathrm{uM}$ with very few cells undergoing apoptosis. To further investigate the relationship between apoptosis and released ions of different alloys, ICP-MS was used to measure ion concentration of alloys during the immersion in cell medium for 7 days. The result was displayed in Fig.3. Ion types and total ion concentration were adopted to evaluate the biocompatibility of the alloys. It can be seen that more $\mathrm{Co}$ and $\mathrm{Cr}$ ions were released into the culture fluid. The ion types and total ion concentration were adopted as the important factors to evaluate the biocompatibility of the materials. Total ion concentration levels at 7 days were as follows: $\mathrm{A}<\mathrm{C}$ $<\mathrm{B}<\mathrm{D}$ which are corresponding to mRNA levels.

These investigations clearly demonstrated that it is more sensitive to study the affect of five dental alloys to L929 cells on molecular level than that on cell level. Metal ions of five dental alloys may induce cell apoptosis by different degree through mitochondrion pathway. The mRNA levels expressed by caspase3 and caspase- 9 were as follows from low to high: $\mathrm{Cu}$ alloy, the negative control and Au alloy, $\mathrm{Co}-\mathrm{Cr}$ alloy, Ag-Pd alloy, and NiCr alloy after 48 hours' culture.

\section{Acknowledgement}

The present work was financially supported by a project (2007225005-2) from the Science and Technology Projects of Liaoning Province, China. Research facilities provided by Institute of Metal Research, Chinese Academy of Sciences are also appreciated.

\section{References}

1. David A and Lober D. In vitro cytotoxicity of orthodontic archwires in cortical cell cultures. Eur J Orthod 26(4): 421436, 2004

2. Al-Hiyasat A S, Darmani $\mathrm{H}$ and Bashabsheh O M. An investigation of the cytotoxic effects of dental casting alloys. Int J Prothodont 16(1): 8-12, 2003

3. Coppi C, Devincenzi CP, Bortolini S and Tiozzo R. A new generation of sterile and radiopaque impression materialsan in vitro cytotoxicity study. J Biomater Appl 22(1): 25-36, 2007

4. Huang TH, Ding SJ and Kao CT. Biocompatibility of various formula root filling materials for primary teeth. Journal of Biomedical Material Research part-B: applied biomaterials 80(2): 486-490, 2007

5. Jia Guang and Liu Shijie. Trypan blue staining and MTT methods used to determine $\mathrm{Cr}$ cytotoxicity. China Occupational Medicine 27(3): 49-52, 2000

6. Wu Jing, Jiang Songhui and Chen Yue. BALB/c3T3 cell toxicity caused by water contained organic matter and heterocystous. China public health 17(11):101-104, 2001

7. Clifford CJ and Downes S. A comparative study of the use of colorimtric assays in the assessment of biocompatibility. J.Mater Sci Mater Medicine 7: 637-646, 1996

8. Fan Chengxiang and Chen Liang. Evaluation of molecular biology in the study of biological materials application status. Foreign Medical Biomedical Engineering Fascicle, 27(6):36-38, 2004

9. Chou L, Firth JD, Uitto VJand Brunette DM. Substratum surface topography alters cell shape and regulates fibronectin mRNA level, mRNA stability, secretion and assembly in human fibroblasts. J Cell Sci 15: 63-73, 1995

10. Ning Li and Liu Jun. The investigation of molecular biocompatibility of biomaterials from the impact on the total amount cellular RNA. Shanghai Bio-Medical Engineering, 19(4): 6-9, 1998

11. Kato S, Akagi T, Sugimura K, Kishida A and Akashi M. Evaluation of biological responses to polymeric biomaterials by RT-PCR analysis IV: study of c-myc, c-fos and p53 mRNA expression. Biomaterials 21(5): 521-527, 2000

12. Domnina Lv and Ivanova OY. Mariginal blebbong during the early stages of TNF-induced apoptosis indicates alteration in actomyosin contractility. Cell Biol Inter 28(6): 471-475, 2004

13. Emanuele S, D’Anneo A, Bellavia G,Vassallo B, Lauricella M, De Blascio A, Vento R and Tesoriere G. Sodium butyrate induces apoptpsis in huan hepatoma cells by a mitochondria/ caspase pathway, associated with degradation of â-catenin, pRb and Bcl-XL. Cancer 40(9): 1441-1452, 2004

14 Isabelle Catelas, Alain Petit, David J. Zukor, Petit a, Zukor DJ, Antoniou J and Huk OL. TNF- $\alpha$ secretion and macrophage mortality induced by cobalt and chromium ions in vitro-Qualitative analysis of apoptosis. Biomaterials 24 : 383-391, 2003

15 Isabelle Catelas, Alain Petit, Hojatollah Vali, Fragiskatos C, Meilleur R, Zukor DJ, Antoniou J and Huk OL. Quantitative analysis of macrophage apoptosis vs. necrosis induced by cobalt andchromium ions in vitro. Biomaterials 26: 24412453, 2005

16 Mekala Gunaratnam and Mary HG. Damage to F-actin and cell death induced by chromium VI and nickel in primary monolayer cultures of rat hepatocytes. Toxicology in Vitro 18: 245-253, 2004 
J.Hard Tissue Biology Vol. 19(2):95-100, 2010 